\title{
Perceptions of healthcare professionals regarding their own body weight in selected public hospitals in Mpumalanga Province, South Africa
}

\author{
M C Phetla, ${ }^{1}$ BSc Dietetics, MPH; L Skaal, ${ }^{2}$ BSc Physiotherapy, MPH, DrPH \\ ${ }^{1}$ Department of Nutrition, School of Health Care Sciences, Sefako Makgatho Health Sciences University, Pretoria, South Africa \\ ${ }^{2}$ Department of Public Health, School of Health Care Sciences, University of Limpopo, Polokwane, South Africa
}

Correspondingauthor: LSkaal (linda.skaal@ul.ac.za, lskaal@ul.ac.za)

\begin{abstract}
Background. Obesity has been cited as a public health problem in both developing and developed countries. There is evidence that rates of obesity have increased among healthcare workers (HCWs) in South Africa (SA), especially those who do night shifts, with a negative effect on health. Perceptions of body weight contribute significantly to the desire to lose weight or not to do so.

Objective. To determine perceptions of HCWs regarding their own body weight in selected public hospitals in Mpumalanga Province, SA. Methods. The study design was a cross-sectional survey. A total of $210 \mathrm{HCWs}$ were sampled. Data were collected using self-administered questionnaires. Anthropometric measurements such as weight and height were objectively measured and body mass indices (BMIs) were calculated.

Results. Of the sample of HCWs $82.4 \%$ were females, with a mean age of 37.8 years. About half (51.9\%) were obese and $21.4 \%$ were overweight. They tended to misperceive their body weight compared with actual BMI classification, with the majority of obese and overweight individuals considering themselves to be of normal weight.

Conclusions. The results indicate that HCWs misclassify their own body weight, which is a risk factor for obesity. It is important to focus on the health of this group of workers, on whom the health of South Africans depends and who should be the drivers of healthy living for all. Correct classification of their own body weight will encourage people to take action in a bid to combat their own and others' obesity.
\end{abstract}

S Afr Med J 2017;107(4):338-341. DOI:10.7196/SAMJ.2017.v107i4.12174

Obesity has been cited as a major public health problem in both developing and developed countries. Studies show that $\sim 29 \%$ of men and $\sim 56 \%$ of women are obese in South Africa (SA). ${ }^{[1-3]}$ Obesity and the problems related to it are not limited to the general public, studies having shown that healthcare workers (HCWs) are obese worldwide, e.g. in $\mathrm{SA}{ }^{[4]}$ the $\mathrm{USA}^{[5]}$ and Brazil. ${ }^{[6]}$ The health of HCWs has been reported as having deteriorated between 1982 and 2004. ${ }^{[7]}$ The burden of non-communicable diseases (NCDs) in SA has quadrupled over the years $1982-2004,{ }^{[8]}$ and a study by Skaal and Pengpid ${ }^{[4]}$ conducted among HCWs showed that $20 \%$ of them had at least one NCD.

Many HCWs are expected to perform night shifts, and shift work has been shown to be a risk factor for obesity. ${ }^{[9]}$ Shift work disrupts the circadian rhythm, leading to weight gain. Comparing body mass indices (BMIs) of day and night shift workers, Biggi et al. ${ }^{[10]}$ found that night shift workers had significantly higher BMIs than day shift workers. This may be because night shift work induces stress, which in turn leads to poor dietary intake, and tends to result in physical inactivity, both of which contribute to obesity. ${ }^{[1]}$

Studies show that the majority of people misperceive their body weight, and HCWs are no exception, ${ }^{[12-14]}$ including HCWs in SA. ${ }^{[4]}$ Weight misperceptions are more common among individuals in developing than developed countries - for example, a cross-sectional study conducted among adults in Pakistan showed that the majority of obese adults in that country did not perceive themselves as obese. ${ }^{[13]}$ Inaccurate perception of body weight predisposes individuals to obesity and its associated health risks.

Body weight perceptions are influenced by psychosocial, sociocultural and socioenvironmental factors ${ }^{[15]}$ ranging from being comfortable about one's body size to lack of knowledge about ideal body weight. ${ }^{[13]}$ Nurses in Nigeria have been reported as perceiving obesity as the sign of 'good living, ${ }^{\text {,[16] }}$ and obesity is often viewed as a sign of wealth and affluence. Body weight perception is influenced by age, level of education, population group, area of residence, gender, race, ethnicity and socioeconomic status. ${ }^{[12,13]}$ Studies have shown that women perceive their body weight more accurately than men, and that people of higher socioeconomic status perceive their weight more accurately than those of lower socioeconomic status, irrespective of their body size. ${ }^{[12,15]}$ Black non-Hispanics ${ }^{[17]}$ and black South Africans ${ }^{[1]}$ have been found to have higher rates of body misconceptions than their white counterparts, and it has been reported that older people tend to misperceive their body weight more than younger ones. ${ }^{[15]}$

Correct body weight perception is required in order for weight loss management strategies to be implemented. Inaccurate weight perception leads to poor weight management. ${ }^{[18]}$ For example, if an obese individual perceives his or her body weight as normal, he or she will not take any action to reduce the weight, whereas a very obese individual who perceives him- or herself as actually obese is likely to seek ways of losing weight.

\section{Objective}

To determine healthcare professionals perceptions of their own body weight in selected public hospitals in Mpumalanga Province, SA.

\section{Methods}

\section{Design and approach}

A quantitative research approach and a cross-sectional descriptive study design were used. Ethical clearance was obtained from 
the Medunsa Research and Ethics Committee (ref. no. MREC/ H/167/2013:PG). Permission to conduct the study was obtained from the Mpumalanga Provincial Department of Health research office (no reference number), and informed consent forms were signed by all participants prior to the study.

\section{The participants}

The total population of HCWs working at Ermelo and Bethal hospitals in Mpumalanga is 435 . The study included only HCWs who consented to participate and were working full time in these two hospitals. Stratified random sampling was used to select $210 \mathrm{HCW}$ in the following strata: nurses, allied health workers and doctors. Sample size was calculated using a 95\% confidence level and 5\% margin of error (Raosoft Inc., USA, 2011), using the following formula:

$$
\begin{aligned}
& x=Z\left({ }^{c} /{ }_{100}\right)^{2} r(100-r) \\
& n={ }^{N x} /\left((N-1) E^{2}+x\right) \\
& E=\operatorname{Sqrt}\left[{ }^{(N-n) x} / n(N-1)\right]
\end{aligned}
$$

where $n$ is the sample size and $E$ the margin of error.

As the numbers in the sample per stratum depended on the population size per profession, more nurses and allied health workers than doctors were included in the study. Two research assistants were trained in anthropometric measurement (weight and height), the correct way of approaching possible participants and recruiting them for the study, and administering the questionnaires.

\section{Data collection}

On the dates of data collection, recruitment was conducted at different times, the HCWs being approached at their respective work stations. Dates were scheduled with them, because it was not practical to meet with all of them at once. During information sessions they were provided with an information leaflet to read and were given the opportunity to decide whether they wanted to participate in the study or not. Those who agreed to participate were allocated numbers that were placed in a hat and then raffled randomly until the required number per stratum had been selected. Day and time of data collection were allocated according to the individual's availability.

Data were collected using self-administered closed-ended questionnaires that captured the sociodemographic characteristics, diseases/health problems and body weight perceptions of the HCWs. Reliability and validity were ensured.

\section{Data analysis}

All data were coded and entered into SPSS version 20.0 (USA) for analysis. Descriptive statistics were used to analyse the frequencies, correlations and means. The $\chi^{2}$ test was used to analyse associations between variables.

\section{Results}

Of the 210 participants, the majority (82.4\%) were female (Table 1 ). The participants' ages ranged from 21 years to 63 years (mean 37.8 , median 37.0 , standard deviation 9.247). The majority (63.8\%) of the participants were $\leq 40$ years of age.

The majority of the participants were not married (64.3\%), were black (83.8\%) and were nurses (69.5\%), and close to half $(47.6 \%)$ were living in urban areas; $56.2 \%$ reported that they participated in physical activity other than that involved in their normal daily routine (Table 1).

\begin{tabular}{ll}
$\begin{array}{l}\text { Table } \mathbf{1 . S} \text { Sociodemographic profile of the study participants } \\
(\boldsymbol{N}=\mathbf{2 1 0})\end{array}$ \\
\hline Variable & $\boldsymbol{n}(\%)$ \\
\hline Sex & $37(17.6)$ \\
$\quad$ Males & $173(82.4)$ \\
Females & \\
Age (yr) & $134(63.8)$ \\
$\leq 40$ & $76(36.2)$ \\
$>40$ & \\
Marital status & $135(64.3)$ \\
Not married & $75(35.7)$ \\
Married & \\
Race & $176(83.8)$ \\
Black & $29(13.8)$ \\
White & $5(2.4)$ \\
Indian & $100(47.6)$ \\
Residence & $54(25.7)$ \\
Urban & $56(26.6)$ \\
Township & \\
Rural & $146(69.5)$ \\
Job title & $45(21.4)$ \\
Nurses & $19(9.0)$ \\
Allied health workers & $118(56.2)$ \\
Doctors & $92(43.8)$ \\
Participate in physical activity & \\
Yes & \\
No & \\
&
\end{tabular}

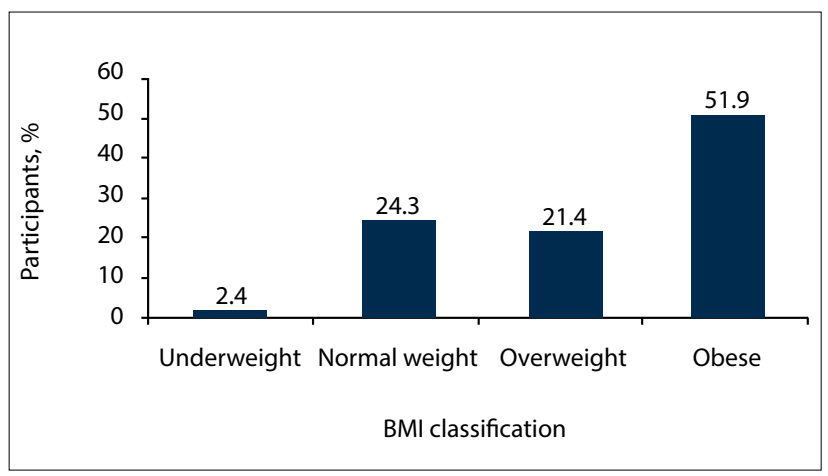

Fig. 1. BMI classifications of the study participants $(\mathrm{N}=210)$.

Fig. 1 shows that just over half (51.9\%) of the participants were obese, $21.4 \%$ were overweight, and only $24.3 \%$ were of normal weight.

Table 2 shows the participants' self-reported health problems and diseases, of which the most common were musculoskeletal problems $(41.0 \%)$, followed by stress (17.6\%), hypertension (14.3\%) and varicose veins $(11.0 \%)$.

Table 3 shows that the close to two-thirds (64.4\%) of the participants who were in fact overweight perceived themselves to be of normal weight, and that $36.7 \%$ of the participants who were obese perceived themselves to be of normal weight.

Table 4 shows that BMI differed significantly according to age $(p=0.000)$, with a higher proportion of older participants (51 60 years) than younger participants $(20-30$ years $)$ being obese $(85.6 \%$ v. $19.3 \%$ for the younger participants). BMI also differed significantly according to gender $(p=0.010)$, with more females (57.2\%) than males $(27.0 \%)$ being obese. There was a significant difference in BMI according to race $(p=0.000)$. 


\section{Discussion}

We found that three-quarters of HCWs in our study were overweight or obese. Other studies have shown that healthcare professionals in SA are no different from the general population. For example, threequarters of HCWs in Pretoria were found to be overweight or obese. ${ }^{[4]}$ HCWs should be role models in their communities and be champions of a healthy lifestyle, ${ }^{[4]}$ but instead they appear to be contributing to SA's obesity epidemic. This is not unique to SA, studies in countries such as Mexico, New Zealand and the UK also having found that a higher than expected proportion of HCWs were obese. ${ }^{[7,19-21]}$ The health of HCWs should be given special attention, as studies have shown that obesity-related diseases can lower productivity and lead to early retirement, apart from the cost implications of caring for patients with these diseases. ${ }^{[22-24]}$

Many studies have shown that females tend to be more obese than males, ${ }^{[23,25,26]}$ and our findings were similar. The healthcare profession is dominated by females; for example, it has been reported that $94 \%$ of nurses are females. ${ }^{[27]}$ Other risk factors associated with obesity are age, race, physical inactivity and poor eating habits. ${ }^{[28]}$ The majority of HCWs in our study were black, which has also been associated with an increased risk of obesity. Furthermore, low levels of activity and poor nutritional status often become more prevalent as individuals grow older.

Obesity predisposes populations to NCDs. ${ }^{[29,30]}$ In our study, a quarter of HCWs reported that they suffered from hypertension,

Table 2. Disease profile/health problems of the study participants $(N=210)$

\begin{tabular}{ll}
\hline Health problem & $\boldsymbol{n}(\%)$ \\
\hline Musculoskeletal problems & $86(41.0)$ \\
Stress & $37(17.6)$ \\
Diabetes mellitus & $15(7.1)$ \\
Hypertension & $30(14.3)$ \\
Heart disease & $10(4.8)$ \\
Varicose veins & $23(11.0)$
\end{tabular}

diabetes and heart disease, and over a third had musculoskeletal problems. It is likely that the majority of our study participants with NCDs were also obese. The high prevalences of hypertension, diabetes mellitus and heart disease among HCWs in both our study and that of Skaal and Pengpid ${ }^{[4]}$ are a matter of concern, and imply that at least one in every ten healthcare workers were suffering from at least one health problem or disease, as has been reported in Mexico. ${ }^{[31]}$ There is a link between musculoskeletal problems and body weight, ${ }^{[29,32]}$ and our study showed a significant association between obesity and the presence of musculoskeletal problems. It is evident that obesity poses an alarming challenge among our healthcare professionals, ranging from NCDs to musculoskeletal problems. The healthcare cost attached to these diseases is already crippling the economy of our country, where billions are being spent on managing NCDs. ${ }^{[3]}$ Other financial burdens include a high rate of staff absenteeism due to ill health, the cost of which may also run into millions of rands. ${ }^{[3,33]}$ Furthermore, service delivery is affected by the inability of workers with obesity-related chronic diseases to function optimally. ${ }^{[34]}$

Our study revealed that half of the obese respondents perceived themselves to be overweight when they were in fact obese, with only a tenth of them correctly perceiving themselves to be obese. Dorosty et al. ${ }^{[35]}$ have proposed that perception of body weight status is an important determinant of weight-related behaviour. It has been suggested that people who did not have any intention of tackling their weight problem were comfortable with their weight, lacked discipline or had lost hope with regard to their weight, which could affect their perceptions of their body weight. ${ }^{[5,36]}$ This was indeed found in our study, where a third of the respondents misclassified their own body weight.

It is of interest that over a third of obese HCWs in our study perceived themselves to be of normal weight, which differs from findings in Iran, where it was reported that women of normal weight were eight times more likely than obese women to misperceive their weight. ${ }^{[35]}$ In our study, both overweight and obese women were more likely to misclassify their weight than women of normal weight. The problem with incorrect classification by an individual of their own

Table 3. Perceived body weight $v$. actual body weight

\begin{tabular}{lllll}
\hline & \multicolumn{4}{c}{ Perceived body weight, $\boldsymbol{n}(\%)$} \\
\cline { 2 - 5 } Actual body weight & Underweight & Normal weight & Overweight & Obese \\
\hline Underweight $(N=5)$ & $1(20.0)$ & $3(60.0)$ & $1(20.0)$ & $0(0)$ \\
Normal weight $(N=51)$ & $1(2.0)$ & $42(82.4)$ & $8(15.6)$ & $0(0)$ \\
Overweight $(N=44)$ & $1(2.2)$ & $29(64.4)$ & $14(31.1))$ & $1(2.2)$ \\
Obese $(N=109)$ & $2(1.8)$ & $40(36.7)$ & $54(49.5)$ & $13(11.9)$
\end{tabular}

Table 4. BMI according to age, gender and race

\begin{tabular}{|c|c|c|c|c|c|c|}
\hline \multirow[b]{2}{*}{ Variables } & \multirow[b]{2}{*}{$N$} & \multicolumn{4}{|c|}{ BMI, $n(\%)$} & \multirow[b]{2}{*}{$p$-value and $\chi^{2}$} \\
\hline & & Underweight & Normal weight & Overweight & Obese & \\
\hline \multicolumn{7}{|l|}{ Age (yr) } \\
\hline$\leq 40$ & 134 & $4(3.0)$ & $46(34.3)$ & $31(23.1)$ & $53(39.5)$ & $p=0.000^{*}$ \\
\hline$>40$ & 76 & $1(1.3)$ & $5(6.6)$ & $14(18.4)$ & $56(73.7)$ & $\chi^{2}=52.910$ \\
\hline \multicolumn{7}{|l|}{ Sex } \\
\hline Female & 173 & $4(2.3)$ & 37 (21.4) & $33(19.1)$ & $99(57.2)$ & $p=0.010^{*}$ \\
\hline Male & 37 & $1(2.7)$ & $14(37.8)$ & $12(32.4)$ & $10(27.0)$ & $\chi^{2}=11.309$ \\
\hline \multicolumn{7}{|l|}{ Race } \\
\hline Black & 176 & $3(1.7)$ & $34(19.3)$ & $38(21.6)$ & $101(57.4)$ & $p=0.000^{*}$ \\
\hline White & 29 & $1(3.4)$ & $14(48.3)$ & $6(20.7)$ & $8(26.7)$ & $\chi^{2}=25.21$ \\
\hline Indian & 5 & $1(20.0)$ & $3(60.0)$ & $1(20.0)$ & $0(0)$ & \\
\hline
\end{tabular}


body weight is that it becomes difficult for them to face the reality that they need to lose weight, or accept that their illnesses are linked to obesity. ${ }^{[3,37,38]}$ Although in a qualitative study conducted in Brazil it was reported that obesity was accompanied by feelings of sadness, shame and isolation, ${ }^{[39]}$ it is more readily accepted if it is prevalent in a community. Individuals may therefore simply resign themselves to their body size.

Another factor that has been found to contribute to misclassification of body weight is culture. Some cultural attitudes lead to women desiring to gain rather than lose weight; for example, if women are expected to be well rounded to be considered as marital prospects, many will do whatever is necessary to improve their chances. ${ }^{[40,41]}$ It has also been argued that position in the family household impacts significantly on an individual's decision whether or not to gain weight. ${ }^{[4]]}$ In African culture obesity is associated with wealth, good health and attractiveness, ${ }^{[42]}$ whereas normal weight and underweight are associated with diseases such as HIV/AIDS, or being poor. ${ }^{[36,42]}$ Since all our respondents fell into the middle-income group, their perceptions may have been affected by enculturation.

\section{Conclusions}

Our results show that it is vitally important to focus on the health of this sector of the workforce, primarily because the health of South Africans depends on them and they should be the drivers of healthy living for all. It is also important to quantify the real cost of obesity at both national and individual levels, to encourage people to take action in a bid to combat it.

A positive development is that the SA government released a national strategic plan on obesity prevention in 2015. ${ }^{[43]}$ This effort needs to be complemented by a healthy healthcare workforce, who are drivers and implementers of this policy.

Acknowledgements. The authors acknowledge the assistance of the Flemish Inter-university Council (VLIR-UOS) and support from the School of Public Health, University of Limpopo.

1. Puoane T, Steyn K, Bradshaw D, Fourie J, Lambert V. Obesity in South Africa: The South African demographic survey. Obes Res 2002;10(10):1038-1048. https://doi.org/10.1038/oby.2002.141

2. Heart and Stroke Foundation, South Africa. South Africa's weighty problem. http://heartfoundation.co.za/ media-releases/national-obesity-week-south-africa\% $\% 2 \% 80 \% 99$ s-weighty-problem (accessed 3 November 2016).

3. Hofman K. Non-communicable diseases in South Africa: A challenge to economic development. S Afr Med J 2014;104(10):647. https://doi.org/10.7196/SAMJ.8727

4. Skaal L, Pengpid S. Obesity and health problems among South African healthcare workers: Do healthcare workers take care of themselves? S Afr Fam Pract 2011;53(6):563-567. https://doi.org/10 1080/20786204.2011.10874153

5. Miller SK, Alpert PT, Cross CL. Overweight and obesity in nurses, advanced practice nurses, and nurse educators. J Am Assoc Nurse Pract 2008;20(5):259-265. https://doi.org/10.1111/j.1745 7599.2008.00319.x

6. Nascimento LC, Mendes IJ. Health profile of workers at a teaching health center. Rev Lat Am Enfermagem 2002;10(4):502-508. https://doi.org/10.1590/\$0104-11692002000400006

7. Chou C, Johnson PI. Health disparities among Americas's healthcare providers: Evidence from the Integrated Health Interview Series, 1982 to 2004. J Occup Env Med 2008;50(6):696-704. https://doi. Integrated Health Interview Series, 1982

8. Norman R, Bradshaw D, Schneider M, et al. A comparative risk assessment for South Africa in 2000 Towards promoting health and preventing disease. S Afr Med J 2007;97(8):637-641.

9. Eberly R, Feldman H. Obesity and shift work in the general population. Internet J Allied Health $\mathrm{Sci}$ Pract 2010;8(3):1-9.

10. Biggi N, Consonni D, Galluzzo V, Sogliani M, Costa G. Metabolic syndrome in permanent night workers. Int J Chronobiol 2008;25(2-3):443-454. https://doi.org/10.1080/07420520802114193

11. Wong H, Wong MK, Wong SY, Lee A. The association between shift duty and abnormal eating behaviour among nurses working in a major hospital: A cross sectional study. Int J Nurs Stud 2010;47(8):1021-1077. https://doi.org/10.1016/j.jinurstu.2010.01.001
12. Paeratakul S, White MA, Williamson DA, Ryan DH, Bray GA. Sex, race/ethnicity, socioeconomic status and BMI in relation to self-perception of overweight. Obes Res 2002;10(5):345-350. https://doi. org/10.1038/oby.2002.48

13. Bhanji S, Khawuja AK, Siddiqui F, Azam I, Kazmi K. Underestimation of weight and its associated factors among overweight and obese adults in Pakistan: A cross sectional study. BMC Public Health 2011;11:263. https://doi.org/10.1186/1471-2458-11-363

14. Duncan JS, Duncan EK, Schofield G. Association between weight perceptions, weight control and body fatness in a multi-ethnic sample of adolescent girls. Public Health Nutr 2011;14(1):93-100. https://doi.org/10.1017/S1368980010000236

15. Howard NJ, Hugo GJ, Taylor AW, Wilson DH. Our perception of weight: Socioeconomic and sociocultural explanations. Obes Res Clin Pract 2008;2(2):71-142. https://doi.org/10.1016/j. orcp.2008.03.003

16. Ogunjimi LO, Ikorok MM, Olayinka YO. Prevalence of obesity among Nigeria nurses: The Akwa Ibom state experience. Int NGO J 2010;5(2):45-49.

17. Dorsey RR, Eberhardt MS, Ogden CL. Racial/ethnic difference in weight perception. Obesity (Silver Spring) 2007;17(4):740-750. https://doi.org/10.1038/oby.2008.603

18. Herring SJ, Nelson DB, Davey A, et al. Determinants of excessive gestational weight gain in urban, ow-income women. Womens Health Issues 2012;22(5):e439-e446. https://doi.org/10.1016/j. whi.2012.05.004

19. World Health Organization. Global prevalence of adult overweight and obesity by region. http:// worldobesity.org/aboutobesity/resources/obesity-data-portal/ (accessed 16 March 2015).

20. Vasquez-Martinez JL, Gomez-Dantes H, Gomez-Garcia H, Lara-Rodriquez ML, Navarrete-Espinosa J, Perez-Perez G. Obesity and overweight in IMSS female workers in Mexico City. Salud Publica Mex 2005;47(4):22-48. https://doi.org/10.1016/j.ijcard.2006.08.023

21. Zapka J, Lemon S, Magner RP, Hale J. Lifestyle behaviours and weight among hospital-based nurses. J Nurs Manag 2009;17(7):853-860. https://doi.org/10.1111/j.1365-2834.2008.00923.x

22. Begley S. As Americas waistline expands, costs soar. Reuters, 2012. http://reuters.com/ article/2012/04/30/us-obesityidUSBRE83T0C820120430 (accessed 30 April 2013).

23. Centers for Disease Control. Overweight and obesity. http://www.cdc.gov/obesity/ (accessed 1 September 2016).

24. Be Active North Carolina Report. The high cost of unhealthy behaviour. 2012. http://forprevention. org/prevention/Document/Download?id=34e9eb7c-236b-4b74-915b-7513f733bd91 (accessed 4 August 2012).

25. Kanter R, Caballero B. Global gender disparities in obesity: A review. Adv Nutr 2012;3(4):491-498. https://doi.org/10.3945/an.112.002063

26. South African Medical Research Council. Media statement. South African women show high levels of obesity and overweight. 29 May 2014. http://mrc.ac.za/Media/2014/14press2014.htm (accessed 27 February 2017).

27. South African Nursing Council. Provincial distribution of nursing manpower versus the population of the Republic of South Africa. 2014. http://sanc.co.za/stats.htm (accessed 8 September 2016).

28. Kruger HS, Puoane T, Senekal M, van der Merwe MT. Obesity in South Africa: Challenges for government and health professionals. Public Health Nutr 2005;8(5):491-500. https://doi.org/10.1079/
goticas government and
PHN2005785

29. Kapitan M. The prevalence of obesity and related risk factors amongst nurses in a public health hospital Kapitan M. The prevalence of obesity and related risk factors amongst nurses in a public he
in KwaZulu-Natal. M Sport Sci dissertation. Durban: University of KwaZulu-Natal, 2010.

30. Mokdad AH, Ford ES, Bowman BA, Vinicor F, Bales VS, Marks IS. Prevalence of obesity, diabetes and obesity-related health risks factors. JAMA 2003;289(1):76-79. https://doi.org/10.1001/jama.289.1.76

31. Gonzalez-Velazquez F, Mendez GF. Cardiovascular risk stratification by means of the SCORE system in healthcare workers in Veracruz, Mexico. Int J Cardiol. 2007;121(1):81-83. https://doi.org/10.1016/j. ijcard.2006.08.023

32. Ehrentraut JL. Overweight and obesity in health care workers in relation to musculoskeletal conditions and weight loss. Master's thesis. Storrs, Conn.: University of Connecticut Graduate School, 2011.

33. Van Nuys K, Globe D, Ng-Mak D, et al. The association between employee obesity and employer costs: Evidence from a panel of US employers. Am J Health Promot 2014;28(5):277-285. https://doi. org/10.4278/ajhp.120905-QUAN-428

34. Institute of Medicine (US) Committee on the Future Health Care Workforce for Older Americans. Retooling for an Aging America: Building the Health Care Workforce. 2: Health Status and Health Care Service Utilization. Washington, DC: National Academies Press, 2008. http://ncbi.nlm.nih.gov/ books/NBK215400/ (accessed 1 May 2008)

35. Dorosty AR, Mehdikhani S, Soutoudeh G, Rahimi A, Koohdani F, Tehrani P. Perception of weight and health status among women working at health centers of Tehran. J Health Popul Nutr 2014;32(1):5867. https://doi.org/10.1111/j.1753-0407.2012.00206

36. Devanathan R, Esterhuizen TM, Govender RD. Overweight and obesity amongst black women in Durban, Kwa-Zulu-Natal: A 'disease' of perception in an area of high prevalence. Afr J Prim Health Care Fam Med 2013;5(1):450-457. https://doi.org/10.4102/phcfm.v5i1.450

37. Akinpelu AO, Oyewole OO, Adekanla BA. Body size perceptions and weight status of adults in a Nigerian rural community. Ann Med Health Sci Res 2015;5(5):358-364. https://doi.org/10.4103/21419248.165247

38. Park E. Overestimation and underestimation: Adolescents' weight perception in comparison to BMIbased weight status and how it varies across socio-demographic factors. J Sch Health 2011;81(2):57-64. https://doi.org/10.1111/j.1746-1561.2010.00561.x

39. Macedo TTS, Portela PP, Palamira CS, Mussi FC. Obese people's perception of their own bodies. Escola Anna Nery Rev Enferm 2015;19(3):505-510. https://doi.org/10.5935/1414-8145.20150067

40. Mvo Z, Dick J, Steyn K. Perceptions of overweight African women about acceptable body size of women and children. Curationis 1999;22(2):27-31.

41. Renzaho AMN. Fat, rich and beautiful: Changing socio-cultural paradigms associated with obesity risk, nutritional status and refugee children from sub-Saharan Africa. Health Place 2004;10(1):105113. https://doi.org/10.1016/S1353-8292(03)00051-0

42. Venter FC, Walsh CM, Slabber M, Bester CJ. Body size perception of African women (24 - 44 years) in Mangaung. J Consum Sci 2009;37:12-23. https://doi.org/10.4314/ffecs.v37i1.48942

43. National Department of Health, South Africa. Strategy for the Prevention and Control of Obesity in South Africa 2015 - 2020. Pretoria: NDoH, 2015. https://health-e.org.za/wp-content/uploads/2015/12/ National-Strategy-for-prevention-and-Control-of-Obesity-4-August-latest.pdf

Accepted 10 January 2017 